\title{
Microscopy and genomic analysis of Mycoplasma parvum strain Indiana
}

\author{
Naíla C do Nascimento ${ }^{1 * \dagger}$, Andrea P dos Santos ${ }^{1 \dagger}$, Yuefeng Chu ${ }^{1,2}$, Ana MS Guimaraes ${ }^{1,4}$, Aubrey N Baird ${ }^{3}$, \\ Ann B Weil ${ }^{3}$ and Joanne B Messick ${ }^{1 *}$
}

\begin{abstract}
Mycoplasma parvum [Eperythrozoon parvum] is the second hemotrophic mycoplasma (hemoplasma) described in pigs. Unlike M. suis, its closest phylogenetic relative, M. parvum, is considered a non-pathogenic bacterium in this host species. Natural infection of a domestic, 6-month-old splenectomized pig with M. parvum strain Indiana is described herein. Light and scanning electron microscopy of the bacteria were performed in addition to whole genome sequencing, analysis, and comparison to the genome of M. suis strain Illinois. Neither clinical signs nor anemia were observed during the infection. Microscopy analyses revealed coccoid to rod- shaped organisms varying from 0.2 to $0.5 \mu \mathrm{m}$; they were observed individually or in short chains by both light and electron microscopy, however less than $30 \%$ of the red blood cells were infected at peak bacteremia. The single circular chromosome of M. parvum was only 564395 bp, smaller than M. genitalium, previously considered the tiniest member of the Mollicutes. Its general genomic features were similar to others in this class and species circumscription was verified by phylogenomic analysis. A gene-by-gene comparison between M. suis and M. parvum revealed all protein coding sequences (CDS) with assigned functions were shared, including metabolic functions, transporters and putative virulence factors. However, the number of CDS in paralogous gene families was remarkably different with about half as many paralogs in M. parvum. The differences in paralogous genes may be implicated in the different pathogenic potential of these two species, however variable gene expression may also play a role. Both are areas of ongoing investigation.
\end{abstract}

\section{Introduction}

Hemotrophic mycoplasmas (class Mollicutes), trivially known as hemoplasmas, are small cell-wall-less bacteria with a unique tropism for the red blood cells (RBC) of a variety of vertebrate hosts. The genome of ten hemoplasmas, eight different species and two strains each of Mycoplasma suis and M. haemofelis, had their genomes sequenced to date; seven of these were completed by our research group [1-10]. Their genomes have a small core of essential genes; however, they rely on the acquisition of most nutrients from their environment to survive. This feature likely plays a key role in the lack of an established in vitro cultivation of these organisms.

Mycoplasma parvum [Eperythrozoon parvum] was first reported in 1950 as a nonpathogenic bacterium of the

\footnotetext{
*Correspondence: ncannes@purdue.edu; jmessic@purdue.edu

${ }^{\dagger}$ Equal contributors

'Department of Veterinary Pathobiology, Purdue University, 725 Harrison Street, 47907 West Lafayette, IN, USA

Full list of author information is available at the end of the article
}

pig [11]. Unlike $M$. suis, its closest relative, M. parvum often accumulates on a single RBC but only a few RBC are infected. Rod and coccoid forms are common in $M$. parvum infection, ranging in size from 0.2 to $0.5 \mu \mathrm{m}$, whereas ring forms are frequent in $M$. suis. The latter form is larger and may be up to $2.5 \mu \mathrm{m}$ in diameter [11]. Infection by $M$. parvum is usually characterized by the absence of clinical signs even in splenectomized pigs; on the contrary, M. suis bacteremia, characterized by fever and icteroanemia, may result in death. In addition, cross-inoculation studies differentiate these two hemoplasmas as separate species as well as from other species of red cell bacteria that infect cattle, sheep, goats, and mice $[11,12]$.

More than 50 years have passed since its first description, and yet less than 10 publications can be found when searching for "Mycoplasma parvum" or "Eperythrozoon parvum" keywords in scientific databases. The two previous reports documenting $M$. parvum infection in pigs 
were based solely on the amplification and sequencing of its 16S rRNA or ribonuclease P RNA genes [13,14]. The sequences of these genes were divergent from those of $M$. suis, sharing only $96 \%$ and $88 \%$ identity, respectively. These molecular studies corroborated previous morphology, pathogenicity, and cross-inoculation studies, suggesting that M. parvum and M. suis were distinct hemoplasma species. Nevertheless, new molecular tools for species circumscription are likely to provide a better resolution for this complex definition, especially when dealing with these uncultivable bacteria. The average nucleotide identity (ANI) analysis of conserved and shared genes between bacterial strains and supporting calculation of tetranucleotide signature correlation index (TETRA), has recently been proposed as a reliable substitute for DNA-DNA hybridization (DDH) [15]. A value for species delineation based on ANI is currently set at $95 \%-96 \%$. The TETRA signature is an alignmentfree parameter and generally correlates with ANI.

We report herein the course of infection with M. parvum in a naturally infected, splenectomized 6-month-old pig, and the complete genome of $M$. parvum strain Indiana. Furthermore, comparative genomic analyses of $M$. parvum with other hemotrophic mycoplasmas were performed, as well as a gene-by-gene comparison between $M$. parvum strain Indiana and $M$. suis strain Illinois to better understand their contrasting pathogenicity.

\section{Material and methods}

\section{Animal and Mycoplasma parvum DNA isolation}

A male domestic 6-month-old pig (Sus scrofa domesticus, mixed breed) was purchased from the Animal Sciences Research and Education Center-ASREC (West Lafayette, IN, USA). While at the farm, this animal was kept in close contact with other pigs fed a commercial feed containing chlortetracycline (100 grams/ton) during growing and finishing stages (from 7-8 weeks to 6 months old), and vaccinated against Mycoplasma hyopneumoniae (RespiSure ${ }^{\circ}$ ER Bac Plus, Pfizer), Erysipelothrix rhusiopathiae, and circovirus. The animal was tested for hemotrophic mycoplasma infection [16] on two separate occasions prior to its arrival at the Purdue Animal Housing Facilities (Purdue University, West Lafayette, IN, USA). A conventional PCR (cPCR) developed in our laboratory, which amplifies a larger product $(\sim 840 \mathrm{bp})$ of the $16 \mathrm{~S}$ rRNA gene of swine hemoplasmas, was also performed [17]. The identity of both $\mathrm{qPCR}$ and $\mathrm{CPCR}$ products was confirmed by Sanger sequencing. The animal was treated according to the Purdue Animal Care and Use Committee (PACUC) protocol number 1111000223 . The pig was fed antibiotic-free commercial feed, as well as water (via a self-controlled nipple waterer) ad libitum during the entire study. Eleven days after its arrival, the animal was splenectomized according to the PACUC protocol. The pig was monitored daily (minimum twice a day) for clinical signs (e.g. elevated body temperature, and direct observation of behavior- BAR status), and blood was collected into EDTA tubes before and following splenectomy (every 2-8 days depending on clinical signs and blood smear evaluation) for monitoring $M$. parvum infection by qPCR [16].

M. parvum strain Indiana was harvested from the blood of the pig at the peak of bacteremia; EDTA-whole blood was centrifuged at $4000 \mathrm{~g}$ for $10 \mathrm{~min}$ and the buffy coat was removed. The remaining red blood cells with $M$. parvum organisms attached were used for the subsequent DNA extraction. Genomic DNA was extracted using Quick-gDNA $^{\text {Tx }}$ MidiPrep kit according to the manufacturer's instructions (Zymo Research, Irvine, CA, USA).

Light and scanning electron microscopy (SEM) of M. parvum Blood smears were prepared from fresh EDTA-blood every 2 days after splenectomy to follow $M$. parvum infection and stained with Giemsa. Photomicrographs were taken using a total magnification of $100 \mathrm{X}$.

For SEM, aliquots of $1.0 \mathrm{~mL}$ of blood infected with $M$. parvum were centrifuged and pellet was resuspended in $1.0 \mathrm{~mL}$ of glutaraldehyde $2.5 \%$ in $0.1 \mathrm{M}$ sodium cacodylate buffer, $\mathrm{pH}$ 7.4, for fixation. Samples were prepared for scanning electron microscopy using standard procedures at Purdue University's Biological Electron Microscopy Facility, and visualized using FEI Titan Krios microscope.

\section{Sequencing and assembly of $M$. parvum strain Indiana genome}

The whole genome was sequenced from paired-end libraries (TruSeq DNA sample preparation kit, Illumina, San Diego, CA, USA) using Illumina HiSeq 2000 (Illumina, Inc., San Diego, CA, USA) at Purdue University Genomics Core Facility. Average reads of about 100 bases were assembled using ABySS 1.2.7 [18]. After assembly resulting from $1000 \times$ genome coverage of the Illumina reads, a single remaining gap was closed using conventional PCR followed by Sanger sequencing in both directions.

\section{Annotation and analyses of the complete genome of $M$. parvum strain Indiana}

NCBI's prokaryotic Genomes Annotation Pipeline 2.0 provided the first pass annotation of M. parvum genome. The annotation tool Manatee (Institute for Genome Sciences (IGS), School of Medicine, University of Maryland) was used to perform manual annotation of the genome and comparative analysis between the genomes of M. parvum and M. suis strain Illinois (described below). Genomic data of other mycoplasmas available in the NCBI database (NCBI, Bethesda, MD, USA) were also used for comparative analyses. 
Metabolic pathways were predicted based on the KEGG pathway database [19] and the study reported by Yus et al. [20]. BLASTclust tool, by Max-Planck Institute for Developmental Biology [21], was used to assign the paralogous gene families with thresholds of $70 \%$ covered length and $30 \%$ sequence identity.

\section{Analyses for species differentiation}

JSpecies software was used to calculate the average nucleotide identity (ANI; MUMmer algorithm) and tetranucleotide signature correlation indexes between selected genomes as previously described [15]. The following genome sequences were used in the analyses: $M$. parvum strain Indiana [CP006771.1], M. suis strain Illinois [CP002525.1], M. suis strain KI3806 [FQ790233.1], $M$. haemofelis strain Ohio2 [CP002808.1], M. haemofelis strain Langford 1 [FR773153.2], M. haemocanis strain Illinois [NC_016638.1], M. wenyonii strain Massachusetts [NC_018149.1], “Candidatus M. haemominutum" strain Birmingham 1 [HE613254.1], and "Candidatus M. haemolamae" strain Purdue [NC_018219]. The thresholds for species circumscription are $94 \%$ and 0.99 for ANIm and tetranucleotide indexes, respectively [15].

\section{Comparative genomics of $M$. parvum and $M$. suis strain Illinois}

Comparative analyses of the whole genome of $M$. parvum and $M$. suis strain Illinois were performed using BLASTp and/or BLASTn of each CDS or gene of one genome against the other and vice versa. BLASTp was applied to identify unique CDS of $M$. parvum or M. suis; a CDS was considered unique when there were no matching sequences with $\geq 80 \%$ coverage and $\geq 40 \%$ or $\geq 90 \%$ coverage and $\geq 30 \%$ identity to the query sequence.

Each unique CDS of $M$. parvum and $M$. suis was analyzed for the identification of the following parameters: subcellular localization and protein sorting signals using PSORTb v3.0.2 [22,23]; signal peptide cleavage sites using SignalP 4.1 [24]; and the presence of lipoproteins using LipoP version 1.0 software [25].

Whole genome synteny (gene order) was compared between $M$. parvum strain Indiana and $M$. suis strain Illinois using SynMap from CoGe [26]. SynMap generates two-dimensional dot-plot synteny maps using a DAGchainer algorithm coupled with BLAST to identify syntenic homologous genes; each dot represents putative homologous genes between any two genomes [27].

\section{Results}

Mycoplasma parvum infection in a splenectomized pig: bacterial loads and clinical signs

A 6-month-old barrow, domestic pig naturally infected with $M$. parvum was used in this study. The dynamics of its $M$. parvum blood load is shown in Figure 1. Briefly, this animal was initially identified as positive using a specific TaqMan qPCR for swine hemoplasmas [16] while still at the farm (ASREC) (days 1 and 3, Figure 1). In addition, a cPCR employed for amplification of $\sim 840 \mathrm{bp}$ fragment of the 16S rRNA gene of swine hemoplasmas was also positive [17]. Sequencing of the qPCR (157 bp) and cPCR (840 bp) products showed 100\% and 99\% identity, respectively, to the $16 \mathrm{~S}$ rRNA sequence described for M. parvum (GenBank: JX489599.1), in contrast to $97 \%$ identity when compared to the $16 \mathrm{~S}$ rRNA sequence of $M$. suis strain Illinois (NCBI: NR_103930.1). Moreover, the sequencing chromatograms showed single peaks along the entire length of the amplicons indicating the presence of a single sequence. These results confirmed that the animal was infected with $M$. parvum and free of M. suis. At day 22, this pig was transferred to the Purdue Animal Housing Facilities, where it remained for 48 days, from April $11^{\text {th }}$ (day 22) to May 29 $9^{\text {th }}$ (day 70) 2013 (Figure 1). The animal was then splenectomized 11 days after its arrival (day 33, Figure 1) according to the Purdue Animal Care and Use Committee protocol (1111000223). Bacterial loads varied from $10^{5}$ to $10^{10}$ organisms $/ \mathrm{mL}$ of blood throughout the course of infection with a peak of bacteremia $\left(10^{10}\right.$ organisms/mL of blood) occurring 12-14 days after its splenectomy (days 45-47, Figure 1). Organisms were only detected on the peripheral blood smears at peak and for $24 \mathrm{~h}$ thereafter. While the pig's body temperature minimally elevated to $103.7^{\circ} \mathrm{F}$ (reference range 101.6-103.6 ${ }^{\circ} \mathrm{F}$ ) [28] at the peak, no overt clinical signs of infection were observed. The pig's hematocrit varied from 30\% (only on one occasion, not at the peak of bacteremia; Figure 1) to $43 \%$, but otherwise remained within the reference interval (32-50\%) throughout the course of infection [29].

\section{Light and Scanning Electron Microscopy (SEM) of $M$. parvum organisms}

A photomicrograph of the peripheral blood smear obtained at the peak of bacteremia with $M$. parvum (day 45, Figure 1) shows the shape and distribution of these bacteria (Figure 2A). As described previously [11], the organisms are small (approximately 0.2-0.5 $\mu \mathrm{m}$ in diameter), and often infect a few RBC with large numbers of organisms on a single RBC (Figure 2). The SEM shows three $M$. parvum organisms on the surface of a red blood cell; their size varied from $0.2-0.5 \mu \mathrm{m}$ in diameter (Figure 2B).

\section{General features of the genome of $M$. parvum strain Indiana}

The general features of the genome of $M$. parvum strain Indiana regarding size, $\mathrm{G}+\mathrm{C}$ content, percentage of coding sequences and paralogous genes were within the range of those described for all hemoplasmas sequenced to date $[1,4-8,10]$ (Table 1$)$. M. parvum's single circular 


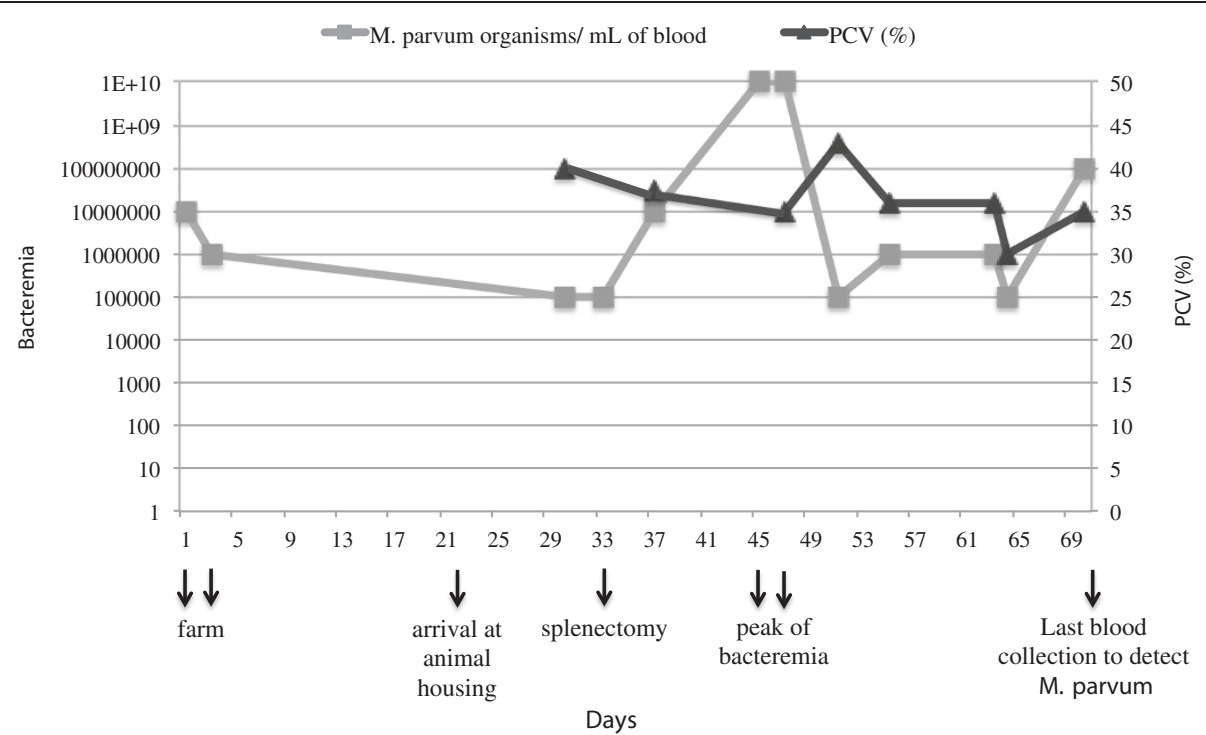

Figure 1 M. parvum loads and PCV of a naturally infected pig before and after splenectomy. The loads of $M$. parvum strain Indiana organisms were detected by TaqMan qPCR on blood samples and the (packed cell volume) PCV was determined before and after splenectomy in the naturally infected pig.

chromosome of $564.395 \mathrm{~Kb}$, the second smallest genome amongst all hemoplasmas, and even smaller than that of M. genitalium, which was previously considered the tiniest member of the Mollicutes (Table 1). It has a $\mathrm{G}+\mathrm{C}$ content of $27 \%$, and like other mycoplasmas, it appears to use the opal stop codon (UGA) for tryptophan. The $16 \mathrm{~S}, 23 \mathrm{~S}$, and 5S rRNA genes are represented as single copies; however, like that of Mycoplasma suis, the $16 \mathrm{~S}$ rRNA gene is separated from the 5S-23S rRNA in a different operon $[1,2]$. Thirty-two tRNA were identified covering all amino acids.

A total of 581 protein-coding sequences (CDS) were predicted and putative functions were assigned and manually verified using the Manatee annotation pipeline: 287 CDS have putative functional identities, representing almost $50 \%$ of the CDS, while the other $50 \%$ were represented by hypothetical proteins. Further, $24.3 \%$ of the genome is dedicated to duplicated genes organized in paralogous families, mostly composed of hypothetical CDS (Table 1).

\section{Hemoplasmas and their phylogenomic relationship based} on ANI and Tetranucleotide signature indexes

A phylogenomic comparison based on average nucleotide identity (ANI) and tetranucleotide signature correlation indexes (tetra) was performed amongst selected hemoplasmas with sequenced genomes (Table 2). $M$. parvum had an ANI varying from $83.6 \%$ to $89.5 \%$ when compared to other hemoplasma genomes, including $M$. suis. The tetra correlation indexes of $M$. parvum with other genomes had a range of 0.47 to 0.88 . Both ANI and tetra correlation indexes were below the cutoff values of $94 \%$ and 0.99 , respectively, for species circumscription.

Comparing all these species of hemoplasmas, ANI and tetra correlation indexes were between 83.6\%-90.25\% and $0.36-0.96$, respectively, correctly separating these organisms as different species of mycoplasmas. On the contrary, strains of the same species (M. suis Illinois and KI3806; M. haemofelis Ohio2 and Langford1) showed ANI and tetranucleotide correlation indexes above the proposed thresholds for species definition, as expected.

\section{M. parvum versus $M$. suis: similarities and differences at the genomic level}

A complete comparison at the genomic level was performed between the genomes of M. parvum strain Indiana and M. suis strain Illinois (Figure 3). The genome of $M$. suis is $178 \mathrm{~Kb}$ bigger than that of M. parvum. SynMap analysis (Additional file 1) indicated a lack of overall gene synteny between $M$. suis and $M$. parvum. Although some conserved blocks of genes, mostly corresponding to operons (e.g. PTS system), were observed, they do not necessarily occur at the same relative position of the genomes. A more detailed, manual analysis shows that the 16S rRNA gene and 5S-23S rRNA operon of M. parvum are located in the first half of its genome (dnaA at position zero), while M. suis copies are in the second half of its genome. Moreover, most of the CDS classified by TIGR role category are organized in a different fashion when comparing both genomes (Figure 3). Despite these rearrangements, both genomes share all CDS with known assigned metabolic or other functions, such as transporters and putative virulence factors; this represents 
Table 1 General features of the genome of Mycoplasma parvum strain Indiana compared to other Mycoplasma species of the pneumoniae group.

\section{Mollicutes}

\begin{tabular}{|c|c|c|c|c|c|c|c|c|c|c|c|c|}
\hline \multirow[b]{3}{*}{$\begin{array}{l}\text { Genomic } \\
\text { feature }\end{array}$} & \multicolumn{12}{|c|}{ Pneumoniae Group } \\
\hline & \multicolumn{8}{|c|}{ Hemothrophic mycoplasmas } & \multicolumn{4}{|c|}{ Mucosal mycoplasmas } \\
\hline & $\begin{array}{l}\text { M. parvum } \\
\text { strain Indiana }\end{array}$ & $\begin{array}{l}\text { M. suis } \\
\text { strain } \\
\text { Illinois }\end{array}$ & $\begin{array}{l}\text { M. } \\
\text { haemofelis } \\
\text { strain } \\
\text { Ohio2 }\end{array}$ & $\begin{array}{l}\text { "Candidatus M. } \\
\text { haemominutum" } \\
\text { strain Birmingham } 1\end{array}$ & $\begin{array}{l}\text { M. } \\
\text { haemocanis } \\
\text { strain } \\
\text { Illinois }\end{array}$ & $\begin{array}{l}\text { M. wenyonii } \\
\text { strain } \\
\text { Massachusetts }\end{array}$ & $\begin{array}{l}\text { "Candidatus M. } \\
\text { haemolamae" } \\
\text { str. Purdue }\end{array}$ & $\begin{array}{l}\text { M. ovis } \\
\text { strain } \\
\text { Michigan }\end{array}$ & $\begin{array}{l}\text { M. } \\
\text { pneumoniae }\end{array}$ & $\begin{array}{l}\text { M. } \\
\text { gallisepticum }\end{array}$ & $\begin{array}{l}\text { M. } \\
\text { genitalium }\end{array}$ & $\begin{array}{l}\text { M. } \\
\text { penetrans }\end{array}$ \\
\hline $\begin{array}{l}\text { Size (base } \\
\text { pairs) }\end{array}$ & 564395 & 742431 & 1155937 & 513880 & 919992 & 650228 & 756845 & 702511 & 816394 & 1012800 & 580076 & 1358633 \\
\hline$G+C$ content & 27 & 31.1 & 38.8 & 35.5 & 35.3 & 33.9 & 39.3 & 31.7 & 40 & 31 & 31.7 & 25.7 \\
\hline $\begin{array}{l}\text { Number of } \\
\text { genes }\end{array}$ & 616 & 884 & 1584 & 582 & 1207 & 687 & 961 & 886 & 733 & 817 & 524 & 1069 \\
\hline $\begin{array}{l}\text { Number of } \\
\text { Coding } \\
\text { sequences } \\
\text { (CDS) }\end{array}$ & 581 & 844 & 1549 & 547 & 1173 & 652 & 925 & 840 & 689 & 763 & 475 & 1037 \\
\hline $\begin{array}{l}\text { CDS with } \\
\text { assigned } \\
\text { functions }\end{array}$ & $287(49.4 \%)$ & $\begin{array}{l}293 \\
(34.7 \%)\end{array}$ & $299(19.3 \%)$ & $219(40 \%)$ & $286(24.3 \%)$ & $309(47.4 \%)$ & $280(30.3 \%)$ & $\begin{array}{l}323 \\
(38.4 \%)\end{array}$ & $333(48.3 \%)$ & $469(61.5 \%)$ & $323(68 \%)$ & $\begin{array}{l}585 \\
(56.4 \%)\end{array}$ \\
\hline \multicolumn{13}{|l|}{$\begin{array}{l}\text { Number of } \\
\text { rRNA }\end{array}$} \\
\hline $16 S$ & 1 & 1 & 1 & 1 & 1 & 1 & 1 & 2 & 1 & 2 & 1 & 1 \\
\hline $23 \mathrm{~S}$ & 1 & 1 & 1 & 1 & 1 & 1 & 1 & 1 & 1 & 2 & 1 & 1 \\
\hline $5 S$ & 1 & 1 & 1 & 1 & 1 & 1 & 1 & 1 & 1 & 3 & 1 & 1 \\
\hline $\begin{array}{l}\text { Number of } \\
\text { tRNA }\end{array}$ & 32 & 32 & 31 & 32 & 31 & 32 & 33 & 32 & 37 & 32 & 36 & 29 \\
\hline $\begin{array}{l}\text { Number of } \\
\text { CDS in } \\
\text { paralogous } \\
\text { families }\end{array}$ & $141(24.3 \%)$ & $\begin{array}{l}361 \\
(42.8 \%)\end{array}$ & $\begin{array}{l}1103 \\
(71.2 \%)\end{array}$ & $134(24.5 \%)$ & 748 (63.8\%) & 371 (56.9\%) & 454 (49.1\%) & $\begin{array}{l}265 \\
(31.5 \%)\end{array}$ & $132(19.1 \%)$ & $110(14.4 \%)$ & $25(5.2 \%)$ & $\begin{array}{l}245 \\
(23.6 \%)\end{array}$ \\
\hline
\end{tabular}




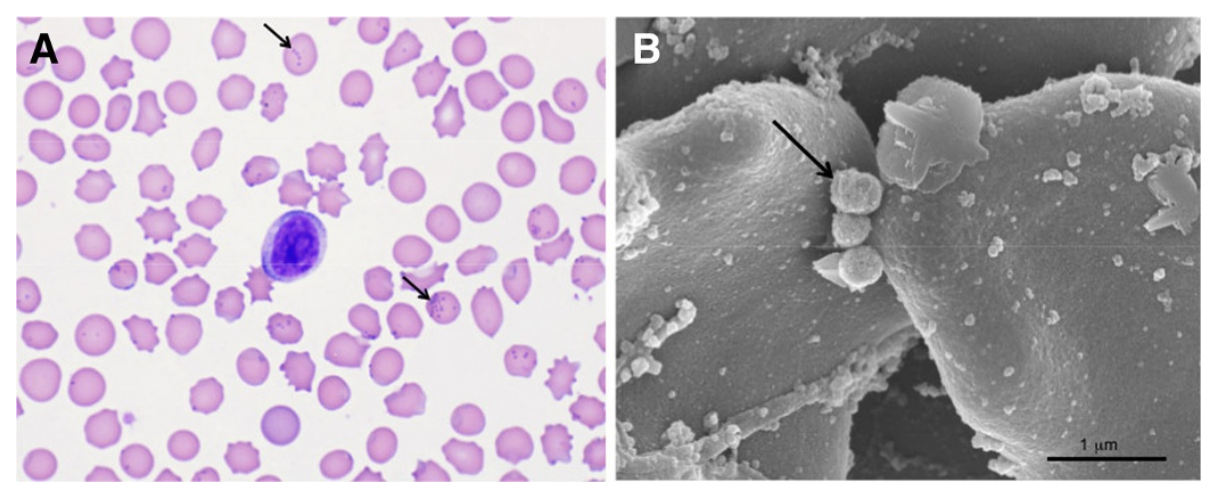

Figure 2 Light microscopy and SEM of $\boldsymbol{M}$. parvum strain Indiana organisms. A) Photomicrograph of a blood smear stained with Giemsa obtained from a pig infected with Mycoplasma parvum (black arrows) at the peak of bacteremia (100X magnification). B) Scanning electron micrograph (SEM) showing red blood cells (RBC) of the pig with M. parvum organisms (black arrow) on the RBC surface. Scale bar, $1.0 \mu \mathrm{m}$.

$49.4 \%$ and $34.7 \%$ of the M. parvum and M. suis genomes, respectively. The remainder of both genomes consisted in hypothetical CDS, most of which are dedicated to paralogous gene families: $M$. parvum has 141 CDS (24.3\%) distributed into 38 paralogous gene families, while M. suis has 361 CDS (42.8\%) in 68 paralogous gene families (Table 1). Twenty-three out of the 38 paralog families of $M$. parvum are represented in the genome of $M$. suis (with a variable number of members per family between the genomes). In contrast, $M$. suis has 40 out of 68 families that are found exclusively in its genome. This difference in paralogous genes is represented by 188 exclusive CDS in the genome of $M$. suis and 64 CDS unique of M. parvum. Considering the hypothetical CDS that are not in paralogous families, both genomes share 74 of these, whereas 63 CDS are found only in M. parvum and 153 CDS only in M. suis. In total, M. parvum has a set of 127 unique CDS, while $M$. suis has $341 \mathrm{CDS}$ found exclusively in its genome.

The set of unique CDS of M. parvum and M. suis were analyzed for subcellular localization and protein sorting signals [22,23], and the presence of signal peptide cleavage sites [24]. Moreover, the presence of lipoproteins was predicted [25] (Table 3). The majority (54.0-66.5\%) of the unique CDS either in paralogous families or not from both $M$. parvum and $M$. suis have an unknown subcellular localization. The remaining CDS are distributed into cytoplasmic membrane, cytoplasmic, and extracellular localization. The unique CDS not in paralogous families from both bacteria are divided mainly into cytoplasmic membrane and cytoplasmic localization, with a smaller number of CDS having a predicted extracellular localization. In contrast, the unique CDS in paralogous families are mostly located in the cytosol, and just a few CDS have cytoplasmic membrane or extracellular localization. The most frequent protein sorting signal amongst all unique CDS is the presence of 1 internal helix, followed by a signal peptide. Analyses of the CDS in paralogous families (details in the Additional file 2) show that a higher number of CDS of $M$. suis $(16.5 \%$ by PSORTb, and $4.25 \%$ by SignalP) have signal peptides compared to M. parvum (1.6\% bt PSORTb, and $0 \%$ by SignalP). Only three lipoproteins (SpII) were identified using LipoP: one unique CDS not paralog of M. parvum, one unique CDS not paralog of $M$. suis, and one unique CDS paralog of M. suis.

\section{Discussion}

The course of infection with M. parvum strain Indiana in the single splenectomized pig evaluated was distinguished from what is commonly seen in $M$. suis infection by the absence of clinical signs, even at the peak of bacteremia. While the bacteremia was apparently fleeting with organisms detected on peripheral blood smears for only a few days after the peak, its persistence at low levels were shown by qPCR. However, these observations are limited to the strain of $M$. parvum described herein and to the animal selected for this study. Further studies should be conducted to evaluate the actual virulence of this isolate, including possible variation among strains and individual pigs. Since the prevalence of $M$. parvum by age is unknown, it is not possible to speculate when this animal got infected with this organism. It is likely, however, that an immune response had developed, which effectively controlled the infection, reducing the bacterial loads. Another possibility is that the use of subtherapeutic doses of antibiotics in the feed at the farm may have controlled the infection. However, the bacteria were not completely eliminated and the animal developed a chronic infection, as is often observed with other hemoplasma species [30]. In contrast, the fever and bacteremia in a splenectomized pig that is infected with $M$. suis is unrelenting and without antibiotics the animal may die [31-33], which was not observed after splenectomy in the animal herein. The impact of acute and chronic hemoplasma infection on the immune system of the host has been poorly explored [34], and is an ongoing area of investigation in our laboratory. 
Table 2 Average nucleotide identity* (ANI) and tetranucleotide signature (Tetra) correlation indexes of selected hemotrophic mycoplasmas.

\begin{tabular}{|c|c|c|c|c|c|c|c|c|c|c|c|c|c|c|c|c|}
\hline & \multicolumn{2}{|c|}{$\begin{array}{l}\text { M. suis str. } \\
\text { Illinois }\end{array}$} & \multicolumn{2}{|c|}{$\begin{array}{l}\text { M. suis str. } \\
\text { KI3806 }\end{array}$} & \multicolumn{2}{|c|}{$\begin{array}{l}\text { M. haemofelis } \\
\text { str. Ohio2 }\end{array}$} & \multicolumn{2}{|c|}{$\begin{array}{l}\text { M. haemofelis } \\
\text { str. Langford }\end{array}$} & \multicolumn{2}{|c|}{$\begin{array}{l}\text { M. haemocanis } \\
\text { str. Illinois }\end{array}$} & \multicolumn{2}{|c|}{$\begin{array}{l}\text { M. wenyonii str. } \\
\text { Massachusetts }\end{array}$} & \multicolumn{2}{|c|}{$\begin{array}{l}\text { "Candidatus M. } \\
\text { haemominutum" } \\
\text { str. Birmingham } 1\end{array}$} & \multicolumn{2}{|c|}{$\begin{array}{l}\text { "Candidatus M } \\
\text { haemolamae" } \\
\text { str. Purdue }\end{array}$} \\
\hline & ANI & Tetra & ANI & Tetra & ANI & Tetra & ANI & Tetra & ANI & Tetra & ANI & Tetra & ANI & Tetra & $\overline{\mathrm{ANI}}$ & Tetra \\
\hline M. parvum str. Indiana & 83.94 & 0.87987 & 83.65 & 0.88079 & 84.66 & 0.47545 & 84.3 & 0.47625 & 84.04 & 0.57312 & 87.33 & 0.75006 & 88.45 & 0.59954 & 89.48 & 0.59873 \\
\hline M. suis str. Illinois & & & 97.74 & 0.997 & 85.41 & 0.365 & 84.83 & 0.366 & 85.59 & 0.452 & 85.24 & 0.75777 & 89.48 & 0.54917 & 89.34 & 0.54636 \\
\hline M. suis str. $\mathrm{KI} 3806$ & & & & & 85.3 & 0.372 & 87.74 & 0.372 & 85.5 & 0.453 & 85.5 & 0.7632 & 89.57 & 0.56269 & 88.6 & 0.55492 \\
\hline M. haemofelis str. Ohio2 & & & & & & & 97.3 & 0.999 & 85.11 & 0.959 & 85.75 & 0.45892 & 84.84 & 0.4172 & 85.73 & 0.60193 \\
\hline M. haemofelis str. Langford & & & & & & & & & 85.21 & 0.962 & 85.84 & 0.45953 & 84.99 & 0.41409 & 85.74 & 0.59729 \\
\hline M. haemocanis str. Illinois & & & & & & & & & & & 85.71 & 0.51169 & 85.58 & 0.45207 & 86.32 & 0.62344 \\
\hline M. wenyonii str. Massachusetts & & & & & & & & & & & & & 90.25 & 0.52911 & 88.21 & 0.62571 \\
\hline "Candidatus M. haemominutum" str. Birmingham 1 & & & & & & & & & & & & & & & 89.83 & 0.63665 \\
\hline
\end{tabular}

The genomes used for the analyses are available in GenBank under the following accession numbers: M. parvum strain Indiana [CP006771.1], M. suis strain Illinois [CP002525.1], M. suis strain KI3806 [FQ790233.1], M. haemofelis strain Ohio2 [CP002808.1], M. haemofelis strain Langford [FR773153.2], M. haemocanis strain Illinois [NC_016638.1], M. wenyonii strain Massachusetts [NC_018149.1], “Candidatus M. haemominutum”" strain Birmingham 1 [HE613254.1], and "Candidatus M. haemolamae" strain Purdue [NC 018219]

*ANI was calculated using MUMmer algorithm in JSpecies software. 


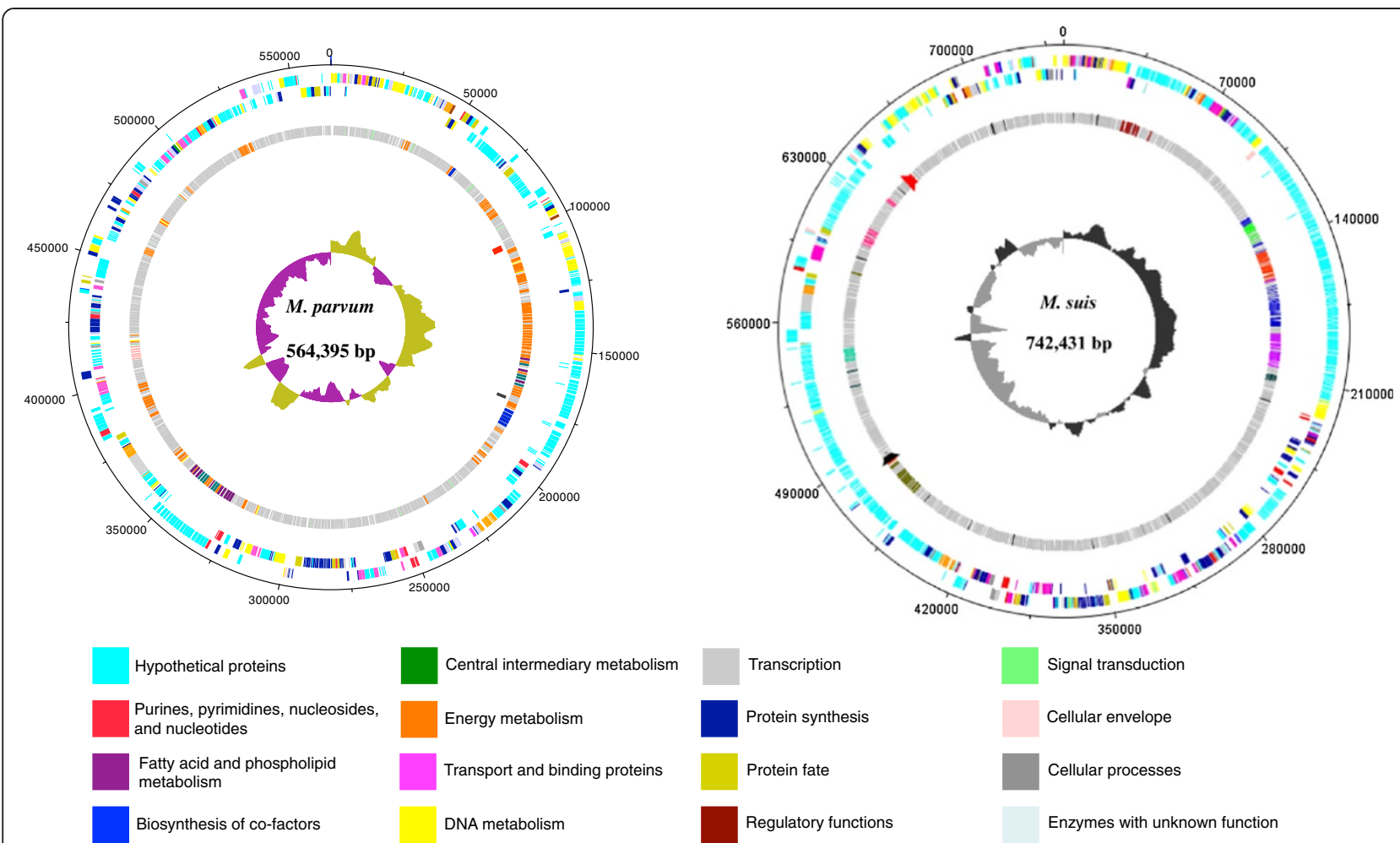

Figure 3 Circular representation of the genomes of $M$. parvum strain Indiana and $M$. suis strain Illinois showing the organization of the coding sequences (CDS). The dnaA gene is at position zero in both genome plots. Outer to inner circles: circle 1: predicted CDS on the positive strand; circle 2: predicted CDS on the negative strand. Each CDS is classified by TIGR role category according to the color designation in the legend below the plots; circle 3: CDS in the largest paralogous gene families with each family represented by a different color in each genome, non-paralogous CDS are light grey. Paralogous families of M. parvum with less than 5 CDS are represented in orange. Black and red marks represent the $16 \mathrm{~S}$ rRNA gene and the 23S/5S rRNA gene operon, respectively. Circle 4: GC skew. The diagrams were generated using Artemis 12.0 DNAPlotter version 1.4, Sanger Institute. (M. suis plot was extracted from Guimaraes AM, Santos AP, SanMiguel P, Walter T, Timenetsky J, Messick JB: Complete genome sequence of Mycoplasma suis and insights into its biology and adaption to an erythrocyte niche. PLoS One 2011, 6:e19574 [1], with permission from the copyright holder).

In this report, M. parvum strain Indiana was described morphologically by light and scanning electron microscopy and its genome was completely sequenced, analyzed and compared to the genome of $M$. suis strain Illinois. A transient bacteremia was demonstrated by light microscopy, whereas SEM confirmed the rod and coccoid morphology, epicellular location, and small size of $M$. parvum (Figure 2B) [11]. Its size, 0.2 to $0.5 \mu \mathrm{m}$, was similar to that reported for other hemoplasmas [35], but remarkably smaller than that reported for $M$. suis with ring forms approaching 1.0 to $2.5 \mu \mathrm{m}$ in diameter [11,36-38]. The level of bacteremia for M. parvum at its peak as shown by qPCR was considerably less (one log) than that previously reported for $M$. suis [16].

M. parvum has the smallest single, circular chromosome of all the Mycoplasma genomes sequenced to date. The characteristics of the $M$. parvum genome, including its small size, low $\mathrm{G}+\mathrm{C}$ content, use of UGA codon to encode tryptophan, and number of tRNA and rRNA were in agreement with those reported for the genomes of other hemoplasmas and are typical of mycoplasmas
$[1,4,6]$. In addition, the percentage of CDS dedicated to paralogous genes $(24.3 \%)$ was similar to that reported for other hemoplasmas $[1-8,10]$. Our group and others have hypothesized that archived sequences of these genes distributed throughout the chromosome play a role in the ability of mycoplasma organisms to persist despite an active host immune response [39].

Phylogenetic studies of M. parvum and M. suis, based on sequence analyses of the 16S rRNA and RNase P genes, suggest that these bacteria are closely related $[13,14]$. Some authors have reported that M. parvum is an immature developmental stage of $M$. suis that is present concurrently with the mature pathogen [33,37]. A phylogenomic approach based on ANI and tetranucleotide signatures that uses whole genome sequence information to compare different organisms provides a better resolution than single gene sequence approaches. It is comparable to the method considered as the gold standard for prokaryotic species definition, the DDH [15]. ANI and tetranucleotide results in this study were below the cut-off values for species definition separating all the organisms included in the 
Table 3 Unique CDS of $M$. parvum strain Indiana and $M$. suis strain Illinois: subcellular localization and protein sorting signals (PSORTb v3.0.2), presence of signal peptide cleavage sites (SignalP), and presence of lipoproteins (LipoP).

\begin{tabular}{|c|c|c|c|c|}
\hline Software \& parameters & $\begin{array}{l}\text { M. parvum - unique CDS } \\
\text { not in paralogous families }\end{array}$ & $\begin{array}{l}\text { M. parvum - unique CDS } \\
\text { in paralogous families }\end{array}$ & $\begin{array}{l}\text { M. suis - unique CDS } \\
\text { not in paralogous families }\end{array}$ & $\begin{array}{l}\text { M. suis - unique CDS } \\
\text { in paralogous families }\end{array}$ \\
\hline \multicolumn{5}{|l|}{ PSORTb } \\
\hline \multicolumn{5}{|l|}{ Subcellular localization: } \\
\hline Unknown & $34(54.0 \%)$ & $37(57.8 \%)$ & $83(54.2 \%)$ & $125(66.5 \%)$ \\
\hline Cytoplasmic Membrane & $13(20.6 \%)$ & $3(4.7 \%)$ & $31(20.3 \%)$ & $12(6.4 \%)$ \\
\hline Cytoplasmic & $11(17.5 \%)$ & $23(35.9 \%)$ & 29 (18.97\%) & $43(22.9 \%)$ \\
\hline Extracellular & $5(7.9 \%)$ & $1(1.6 \%)$ & $10(6.53 \%)$ & $8(4.2 \%)$ \\
\hline \multicolumn{5}{|l|}{ Features: } \\
\hline 1 internal helix found & $30(47.6 \%)$ & $20(31.25 \%)$ & $77(50.3 \%)$ & $153(81.4 \%)$ \\
\hline 2 internal helices found & 0 & 0 & $7(4.6 \%)$ & 0 \\
\hline 3 internal helices found & 0 & 0 & $2(1.3 \%)$ & 0 \\
\hline Signal peptide detected & $3(4.8 \%)$ & $1(1.6 \%)$ & $18(11.8 \%)$ & $31(16.5 \%)$ \\
\hline None & $30(47.6 \%)$ & $43(67.15 \%)$ & 49 (32\%) & $4(2.1 \%)$ \\
\hline \multicolumn{5}{|l|}{ SignalP } \\
\hline YES & $3(4.8 \%)$ & 0 & $11(7.2 \%)$ & $8(4.2 \%)$ \\
\hline NO & $60(95.2 \%)$ & $64(100 \%)$ & 142 (92.8\%) & $180(95.8 \%)$ \\
\hline \multicolumn{5}{|l|}{ LipoP } \\
\hline Spl & $8(12.7 \%)$ & $9(14.0 \%)$ & $36(23.5 \%)$ & $65(34.6 \%)$ \\
\hline Spll & 0 & $1(1.6 \%)$ & $1(0.65 \%)$ & $1(0.53 \%)$ \\
\hline TMH & $2(3.2 \%)$ & $3(4.7 \%)$ & $18(11.8 \%)$ & $29(15.4 \%)$ \\
\hline None & $53(84.1 \%)$ & $51(79.7 \%)$ & 98 (64.05\%) & 93 (49.47\%) \\
\hline Total & 63 & 64 & 153 & 188 \\
\hline
\end{tabular}

PSORTb: results were obtained using the output for Gram-negative bacteria without outer membrane.

SignalP: YES: signal peptide present, NO: signal peptide absent.

LipoP: Spl: signal peptide (signal peptidase I), Spll: lipoprotein signal peptide (signal peptidase II), TMH: $\mathrm{n}$-terminal transmembrane helix. Note from the software: TMH is generally not a very reliable prediction and should be tested. This part of the model is mainly there to avoid transmembrane helices being falsely predicted as signal peptide.

analyses as distinct species of hemotrophic mycoplasmas. M. parvum is, indeed, a distinct species infecting the pig. Further, strains of the same species were clearly distinguished by ANI and tetra scores above the proposed threshold.

M. parvum and $M$. suis, share the same host, the pig; the same environment, the blood; and are phylogenetically, the closest related relatives of one another $[13,14]$. However, the interaction of these bacteria with their host is completely distinct. $M$. suis may cause life threatening hemolytic anemia during acute infection [30,40], while the strain of $M$. parvum shown in this study, and in agreement with previous reports about this organism [11], caused no clinical signs even at the peak of bacteremia in a young, splenectomized pig. At the genomic level, these bacteria are remarkably similar: they share all CDS with known functions. Their genomic synteny, however, is not well conserved. This loss of conservation in the gene order is expected, as different species of hemoplasmas rarely share large syntenic regions, with the exception of M. haemofelis and M. haemocanis [41].
Nevertheless, the genome of $M$. parvum has orthologous for all the CDS with metabolic functions identified in the genome of $M$. suis, implying that their metabolic pathways work very similarly and they have the same requirements for many nutrients to be acquired from the blood environment [1]. The putative virulence factors described for the $M$. suis genome are also present in M. parvum, which raises the question about what is different between these hemoplasmas that reflects in their contrasting pathogenicity. A gene-by-gene comparison between these organisms revealed that their only difference at the genomic level relies in the hypothetical CDS, mostly dedicated to paralogous gene families. M. suis has 40 paralogous families that are exclusive to its genome, while $M$. parvum has 15 families that are not found in M. suis (Additional file 2). In addition, the largest paralogous family (37 CDS) of $M$. suis is unique. Interestingly, the set of unique paralogous CDS of $M$. suis have a higher percentage of signal peptides detected compared to M. parvum CDS; this might indicate that these CDS are secreted or inserted into the membrane and therefore they could play an 
important role in the pathogenicity of $M$. suis as reported for other bacteria $[42,43]$. The differences regarding the percentages of signal peptides detected by all three software (PSORTb, SignalP, and LipoP) are due to their distinct prediction algorithms. PSORTb is the only tool amongst the three applied in this study that provides an output for Gram-negative bacteria with no outer membrane or cell wall. It is presumed more accurate for $\mathrm{Myco-}$ plasma species, which although more phylogenetically similar to Gram-positive organisms, lack a peptidoglycan cell wall.

The maintenance of paralogous gene families in their genomes appears to be a high priority among the hemoplasmas. A prominent role for paralogous genes in the development of antigenic variation has been reported for bacterial species of the genus Anaplasma, Ehrlichia, Borrelia and Mycoplasma and linked to virulence as well as persistence of these infections [44]. It is tempting to speculate that differences in paralogous families between $M$. parvum and $M$. suis may be implicated in their differing pathogenic potential. However, this might also be due to variable expression of core genes, especially genes encoding putative virulence factors or to the presence and variable expression of regulatory RNA. The latter has been previously reported for pathogenic versus non-pathogenic bacteria species of Listeria [45], while variable expression of virulence genes was observed for different strains of Escherichia coli [46], and Listeria monocytogenes [47]. An investigation on the differences at the RNA level between M. parvum and M. suis is warranted, and it is an ongoing project in our laboratory.

\section{Nucleotide sequence accession number}

The genome of M. parvum strain Indiana was deposited in GenBank under the accession number [CP006771.1].

\section{Additional files}

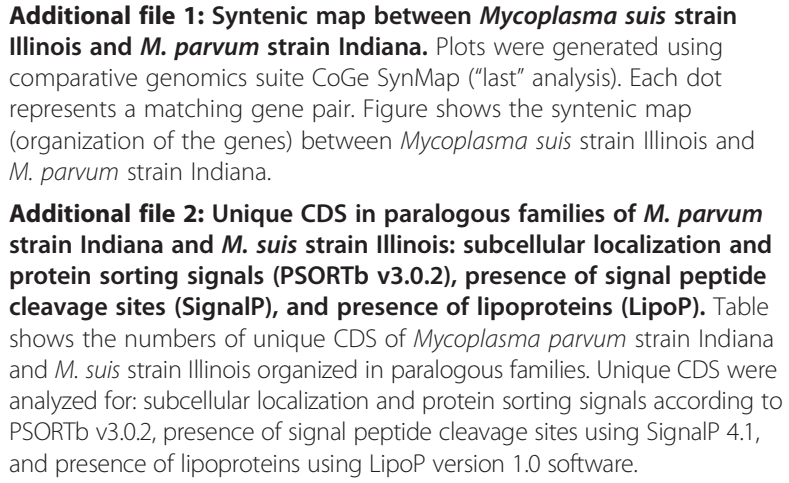

Additional file 2: Unique CDS in paralogous families of $M$. parvum strain Indiana and $M$. suis strain Illinois: subcellular localization and protein sorting signals (PSORTb v3.0.2), presence of signal peptide cleavage sites (SignaIP), and presence of lipoproteins (LipoP). Table shows the numbers of unique CDS of Mycoplasma parvum strain Indiana and M. suis strain Illinois organized in paralogous families. Unique CDS were analyzed for: subcellular localization and protein sorting signals according to PSORTb v3.0.2, presence of signal peptide cleavage sites using SignalP 4.1, and presence of lipoproteins using LipoP version 1.0 software.

\section{Competing interests}

The authors declare that they have no competing interests.

\section{Authors' contributions}

Conceived and designed experiments: NCN, APS, YC, AMSG, JBM. Performed experiments: NCN, APS, YC, AMSG, JBM. Analyzed the data: NCN, APS, YC, AMSG, JBM. Anesthesia and splenectomy: ANB, ABW. Wrote and reviewed the paper: NCN, APS, YC, AMSG, ANB, ABW, JBM. All authors read and approved the final manuscript.

\section{Acknowledgements}

We are extremely grateful to The Genomic Core Facility at Purdue University for constructing the library, running the HiSeq 2000 and performing the ABySS assembly. We also thank the University of Maryland's Institute of Genomic Sciences, which provided us with the manual annotation pipeline Manatee. This work was kindly supported by the Morris Animal Foundation (grant D10FE-0042), and the Brazilian government through CNPq Fellowship Program (Conselho Nacional de Desenvolvimento Científico e Tecnológico) for Postdoctoral Researcher to Dr do Nascimento.

\section{Author details}

'Department of Veterinary Pathobiology, Purdue University, 725 Harrison Street, 47907 West Lafayette, IN, USA. ${ }^{2}$ State Key Laboratory of Veterinary Etiological Biology, Lanzhou Veterinary Research Institute of CAAS, Lanzhou, China. ${ }^{3}$ Department of Veterinary Clinical Sciences, Purdue University, 625 Harrison Street, 47907 West Lafayette, IN, USA. ${ }^{4}$ Present address: Department of Animal Health and Preventive Veterinary Medicine, College of Veterinary Medicine and Animal Science of University of São Paulo, São Paulo, Brazil.

Received: 26 March 2014 Accepted: 6 August 2014

Published: 13 August 2014

\section{References}

1. Guimaraes AM, Santos AP, SanMiguel P, Walter T, Timenetsky J, Messick JB: Complete genome sequence of Mycoplasma suis and insights into its biology and adaption to an erythrocyte niche. PLoS One 2011, 6:e19574

2. Oehlerking J, Kube M, Felder KM, Matter D, Wittenbrink MM, Schwarzenbach S, Kramer MM, Hoelzle K, Hoelzle LE: Complete genome sequence of the hemotrophic Mycoplasma suis strain KI3806. J Bacteriol 2011, 193:2369-2370.

3. Barker EN, Helps CR, Peters IR, Darby AC, Radford AD, Tasker S: Complete genome sequence of Mycoplasma haemofelis, a hemotropic mycoplasma. J Bacteriol 2011, 193:2060-2061.

4. Santos AP, Guimaraes AMS, Do Nascimento NC, Sanmiguel PJ, Martin SW, Messick JB: Genome of Mycoplasma haemofelis, unraveling its strategies for survival and persistence. Vet Res 2011, 42:102.

5. Barker EN, Darby AC, Helps CR, Peters IR, Hughes MA, Radford AD, Novacco M, Boretti FS, Hofmann-Lehmann R, Tasker S: Genome sequence for "Candidatus Mycoplasma haemominutum," a low-pathogenicity hemoplasma species. J Bacterio/ 2012, 194:905-906.

6. Do Nascimento NC, Santos AP, Guimaraes AM, Sanmiguel PJ, Messick JB: Mycoplasma haemocanis - the canine hemoplasma and its feline counterpart in the genomic era. Vet Res 2012, 43:66.

7. Dos Santos AP, Guimaraes AM, Do Nascimento NC, SanMiguel PJ, Messick JB: Complete genome sequence of Mycoplasma wenyonii strain Massachusetts. J Bacteriol 2012, 194:5458-5459.

8. Guimaraes AM, Toth B, Santos AP, Do Nascimento NC, Kritchevsky JE, Messick JB: Genome sequence of "Candidatus Mycoplasma haemolamae" strain purdue, a red blood cell pathogen of alpacas (Vicugna pacos) and llamas (Lama glama). J Bacteriol 2012, 194:6312-6313.

9. Do Nascimento NC, Dos Santos AP, Chu Y, Guimaraes AM, Pagliaro A, Messick JB: Genome sequence of Mycoplasma parvum (formerly Eperythrozoon parvum), a diminutive hemoplasma of the pig. Genome Announc 2013, 1:pii:e00986-13.

10. Deshuillers PL, Santos AP, Do Nascimento NC, Hampel JA, Bergin IL, Dyson MC, Messick JB: Complete genome sequence of Mycoplasma ovis strain Michigan, a hemoplasma of sheep with two distinct 16S rRNA genes. Genome Announc 2014, 2:e01235-13.

11. Splitter EJ: Eperythrozoon suis n. sp. and Eperythrozoon parvum n. sp., 2 new blood parasites of swine. Science 1950, 111:513-514

12. Seamer J: Studies with Eperythrozoon parvum Splitter, 1950. Parasitology $1960,50: 67-80$.

13. Zhou RQ, Nie K, Huang HC, Hu SJ, Zhou ZY, Luo HL: Phylogenetic analysis of Mycoplasma suis isolates based on 16S rRNA gene sequence in China. Vet Res Commun 2009, 33:855-863. 
14. Watanabe $Y$, Fujihara M, Obara H, Nagai K, Harasawa R: Two genetic clusters in swine hemoplasmas revealed by analyses of the 16S rRNA and RNase P RNA genes. J Vet Med Sci 2011, 73:1657-1661

15. Richter M, Rosselló-Móra R: Shifting the genomic gold standard for the prokaryotic species definition. Proc Natl Acad Sci U S A 2009, 106:19126-19131.

16. Guimaraes AMS, Vieira RFC, Polleto R, Vemulapalli R, Santos AP, De Moraes W, Cubas ZS, Santos LC, Marchant-Forde JN, Timenetsky J, Biondo AW, Messick JB: A quantitative TaqMan PCR assay for the detection of Mycoplasma suis. J Appl Microbiol 2011, 111:417-425

17. Messick JB, Cooper SK, Huntley M: Development and evaluation of a polymerase chain reaction assay using the $16 \mathrm{~S}$ rRNA gene for the detection or Eperythrozoon suis infection. J Vet Diagn Invest 1999, 11:229-236.

18. Simpson JT, Wong K, Jackman SD, Schein JE, Jones SJ, Birol I: ABySS: a parallel assembler for short read sequence data. Genome Res 2009, 19:1117-1123.

19. Ogata H, Goto S, Sato K, Fujibuchi W, Bono H, Kanehisa M: KEGG: Kyoto encyclopedia of genes and genomes. Nucleic Acids Res 1999, 27:29-34.

20. Yus E, Maier T, Michalodimitrakis K, Van Noort V, Yamada T, Chen WH, Wodke JA, Güell M, Martínez S, Bourgeois R, Kühner S, Raineri E, Letunic I, Kalinina OV, Rode M, Herrmann R, Gutiérrez-Gallego R, Russell RB, Gavin AC, Bork P, Serrano L: Impact of genome reduction on bacterial metabolism and its regulation. Science 2009, 326:1263-1268.

21. Biegert A, Mayer C, Remmert M, Söding J, Lupas AN: The MPI bioinformatics toolkit for protein sequence analysis. Nucleic Acids Res 2006, 34:W335-W339.

22. Nakai K, Horton P: PSORT: a program for detecting sorting signals in proteins and predicting their subcellular localization. Trends Biochem Sci 1999, 24:34-36.

23. Yu NY, Wagner JR, Laird MR, Melli G, Rey S, Lo R, Dao P, Sahinalp SC, Ester M, Foster LJ, Brinkman FS: PSORTb 3.0: improved protein subcellular localization prediction with refined localization subcategories and predictive capabilities for all prokaryotes. Bioinformatics 2010, 26:1608-1615.

24. Petersen TN, Brunak S, Von Heijne G, Nielsen H: SignalP 4.0: discriminating signal peptides from transmembrane regions. Nat Methods 2011, 8:785-786.

25. Juncker AS, Willenbrock H, Von Heijne G, Brunak S, Nielsen H, Krogh A Prediction of lipoprotein signal peptides in Gram-negative bacteria. Protein Sci 2003, 12:1652-1662.

26. CoGePedia [https://www.genomevolution.org/wiki/index.php/Main_Page].

27. SynMap whole genome synteny [https://genomevolution.org/CoGe/ SynMap.pl].

28. Robertshaw D: Temperature regulation and thermal environment. Dukes Physiology of Domestic Animals. $12^{\text {th }}$ edition. Edited by Reece WO. New York: Cornell University Press; 2004

29. Thorn CE: Normal hematology of the pig. Schalm's Veterinary Hematology. $5^{\text {th }}$ edition. Edited by Feldman BF, Zinkl JG, Jain NC. Philadelphia: Lippincott Williams and Wilkins; 2000:1089-1095.

30. Messick JB: Hemotrophic mycoplasmas (hemoplasmas): a review and new insights into pathogenic potential. Vet Clin Pathol 2004, 33:2-13.

31. Heinritzi K, Peteranderl W, Plank G: Eperythrozoon infection in swine: effect on the acid-base balance and the glucose, lactate and pyruvate content of venous blood. Dtsch Tierarztl Wochenschr 1990, 97:31-34 (in German).

32. Heinritzi K, Plank G: The effect of Eperythrozoon suis infection on the osmotic fragility of erythrocytes. Berl Munch Tierarztl Wochenschr 1992, 105:380-383.

33. Dent BT, Stevens KA, Korvick DL, Clymer JW: Mycoplasma suis infection in pigs after splenectomy. Lab Anim (NY) 2013, 42:125-128 (in German).

34. Novacco M, Boretti FS, Franchini M, Riond B, Meli ML, Hofmann-Lehmann R: Protection from reinfection in "Candidatus Mycoplasma turicensis"-infected cats and characterization of the immune response. Vet Res 2012,43:82.

35. Neimark H, Hoff B, Ganter M: Mycoplasma ovis comb. nov. (formerly Eperythrozoon ovis), an epierythrocytic agent of haemolytic anaemia in sheep and goats. Int J Syst Evol Microbiol 2004, 54:365-371.

36. Pospischil A, Hoffmann R: Eperythrozoon suis in naturally infected pigs: a light and electron microscopic study. Vet Pathol 1982, 19:651-657.

37. Liebich $\mathrm{HG}$, Heinritzi K: Light and electron microscopic studies of Eperythrozoon suis. Tierarztl Prax 1992, 20:270-274 (in German).

38. Groebel K, Hoelzle K, Wittenbrink MM, Ziegler U, Hoelzle LE: Mycoplasma suis invades porcine erythrocytes. Infect Immun 2009, 77:576-584.

39. Citti C, Nouvel LX, Baranowski E: Phase and antigenic variation in mycoplasmas. Future Microbiol 2010, 5:1073-1085.
40. Strait EL, Hawkins PA, Wilson WD: Dysgalactia associated with Mycoplasma suis infection in a sow herd. J Am Vet Med Assoc 2012, 241:1666-1667.

41. Guimaraes AM, Santos AP, Do Nascimento NC, Timenetsky J, Messick JB: Comparative genomics and phylogenomics of hemotrophic mycoplasmas. PLOS ONE 2014, 9:e91445

42. Saleh MT, Fillon M, Brennan PJ, Belisle JT: Identification of putative exported/secreted proteins in prokaryotic proteomes. Gene 2001, 269:195-204.

43. Leversen NA, De Souza GA, Målen H, Prasad S, Jonassen I, Wiker HG: Evaluation of signal peptide prediction algorithms for identification of mycobacterial signal peptides using sequence data from proteomic methods. Microbiology 2009, 155:2375-2383.

44. Palmer $\mathrm{GH}$ : The highest priority: what microbial genomes are telling us about immunity. Vet Immunol Immunopathol 2002, 85:1-8.

45. Wurtzel O, Sesto N, Mellin JR, Karunker I, Edelheit S, Bécavin C, Archambaud C, Cossart P, Sorek R: Comparative transcriptomics of pathogenic and non-pathogenic Listeria species. Mol Syst Biol 2012, 8:583.

46. Dowd SE, Ishizaki H: Microarray based comparison of two Escherichia coli 0157:H7 lineages. BMC Microbiol 2006, 6:30.

47. Severino P, Dussurget O, Vêncio RZ, Dumas E, Garrido P, Padilla G, Piveteau P Lemaitre JP, Kunst F, Glaser P, Buchrieser C: Comparative transcriptome analysis of Listeria monocytogenes strains of the two major lineages reveals differences in virulence, cell wall, and stress response. Appl Environ Microbiol 2007, 73:6078-6088.

doi:10.1186/s13567-014-0086-7

Cite this article as: do Nascimento et al:: Microscopy and genomic analysis of Mycoplasma parvum strain Indiana. Veterinary Research 2014 45:86.

\section{Submit your next manuscript to BioMed Central and take full advantage of:}

- Convenient online submission

- Thorough peer review

- No space constraints or color figure charges

- Immediate publication on acceptance

- Inclusion in PubMed, CAS, Scopus and Google Scholar

- Research which is freely available for redistribution 